AMERICAN RESISTANCE 


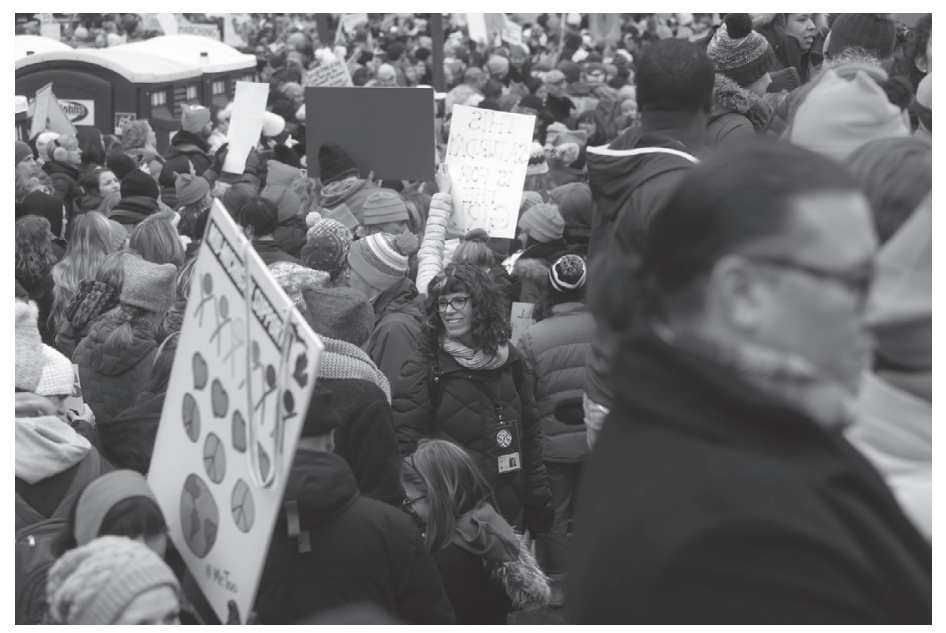

Surveying the crowd at the 2019 Women's March in Washington, DC. 


\title{
AMERICAN RESISTANCE
}

\author{
From the Women's March to the \\ Blue Wave
}

DANA R. FISHER

Columbia University Press

New York 


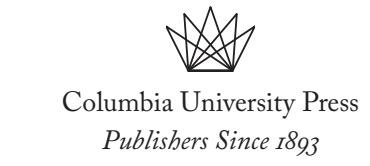

New York Chichester, West Sussex

cup.columbia.edu

Copyright (C) 2019 Dana R. Fisher

All rights reserved

A complete cataloging-in-publication record is available from the Library of Congress.

ISBN 978-o-23I-I8764-o (cloth : alk. paper)

ISBN 978-o-23I-54739-o (e-book)

LCCN 2019018989

Columbia University Press books are printed on permanent and durable acid-free paper.

Printed in the United States of America

Cover design: Noah Arlow 